\title{
Avaliação da Assistência Oncológica
}

\author{
Cancer care evaluation
}

O s gestores do Sistema Ú nico de Saúde SUS, em todas as suas esferas, assim como os administradores das instituições de saúde que compõem esse sistema, necessitam de diretrizes e normas técnicas que os apóiem no exercício de suas responsabilidades. Parâmetros para planejamento, programação, controle e avaliação dos serviços prestados são essenciais para que essas responsabilidades sejam exercidas sob a garantia da prestação de serviços com suficiência e qualidade.

Nesse mister, faz-se necessário o discernimento de que se estrutura um sistema de saúde sobre bases de necessidades populacionais e não da simples oferta de serviços e menos ainda de uma oferta seletiva de procedimentos médico-hospitalares. A dissociação da realidade conseguiu gerar distorções na montagem do sistema de saúde brasileiro e na própria oferta de serviços que, a exemplo daqueles que compõem a assistência oncológica, pecam pela dificuldade de acesso, pulverização da oferta e concentração de interessena prestação daqueles dealtacomplexidade.

Isso, sem contar que, conforme sói ocorrer, os encaminhamentos e fluxos do sistema nem sempre são adequadamente estabelecidos ou controlados por quem de responsabilidade pública, no sentido de salvaguardar a eqüidade do acesso e a necessária integralidade assistencial.

Chocam os exemplos de 45 tomógrafos para cada 2,3 milhões de habitantes de Belo H orizonte, contra 6 em Paris para cada 2,4 milhões; da produção bem menor do que a capacidade instalada de instituições de saúde; da suficiência numérica de equipamentos que se torna deficitária por sua baixa produção e desigual distribuição regional, como se observa com os mamógrafos instalados; e da superoferta de unidades prestadoras de serviços que resulta do excesso de cadastramento de unidades incompletas ou de instituições múltiplas que compartilham 0 mesmo corpo funcional essencial às suas atividades especializadas.

No Brasil, é preciso deixar para trás o alarde equivocado que alguns fazem de situações previsíveis e passar a congregar os esforços de todos os que sofrem e se envolvem com um problema, como, por exemplo, o câncer, para caminhar no mesmo caminho das práticas consistentes e efetivas.

A prevenção e o controle dessa doença são complexos, por multidisciplinares, multiprofissionais e multifatoriais, e por ela representar um duplo desafio para os países em desenvolvimento, que enfrentam aquelas neoplasias malignas persistentes, da pobreza, e aquelas emergentes, das sociedades desenvolvidas.

O sgráficos de 1 a 3 mostram séries temporais da mortalidade por câncer em países de há muito desenvolvidos (Austrália e C anadá) e em franco desenvolvimento (Espanha), todos com curvas ascendentes, como no Brasil (gráfico 4), com tendência ao plateau nos dois primeiros países e ainda em progressão nos dois últimos. Aqueles países têm taxas por 100 mil habitantes maiores do que as do Brasil. I sso faz parecer contraditório que, nos países em desenvolvimento, o objetivo não seja propriamente reduzir a mortalidade por câncer. N eles, o que mais importa é utilizar 0 conhecimento disponível e as experiências de longo prazo vividas por páses desenvolvidos para diminuir o número de mortes, evitáveis ou prematuras, causadas por esta doença. Certamente, a análise por localização tumoral mostraria outras diferenças entre as taxas de mortalidade de países em diferentes estágios de desenvolvimento. 
G ráfico 1: Mortalidade por todas as neoplasias, por 100.000 homens e 100.000 mulheres, Austrália, entre 1950 e 1998.

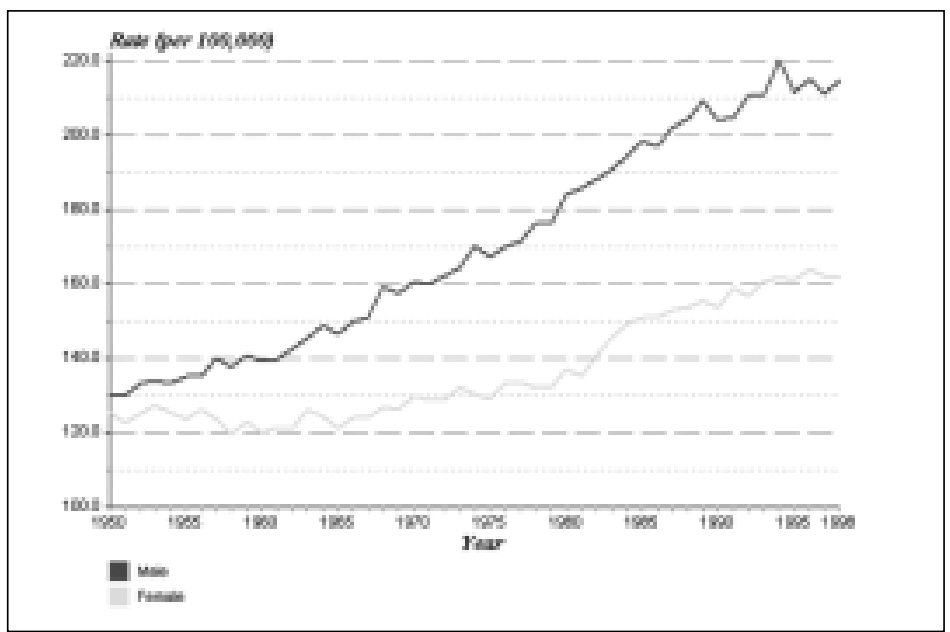

G ráfico 2: Mortalidade por todas as neoplasias, por 100.000 homens e 100.000 mulheres, Espanha, entre 1951 e 1998.

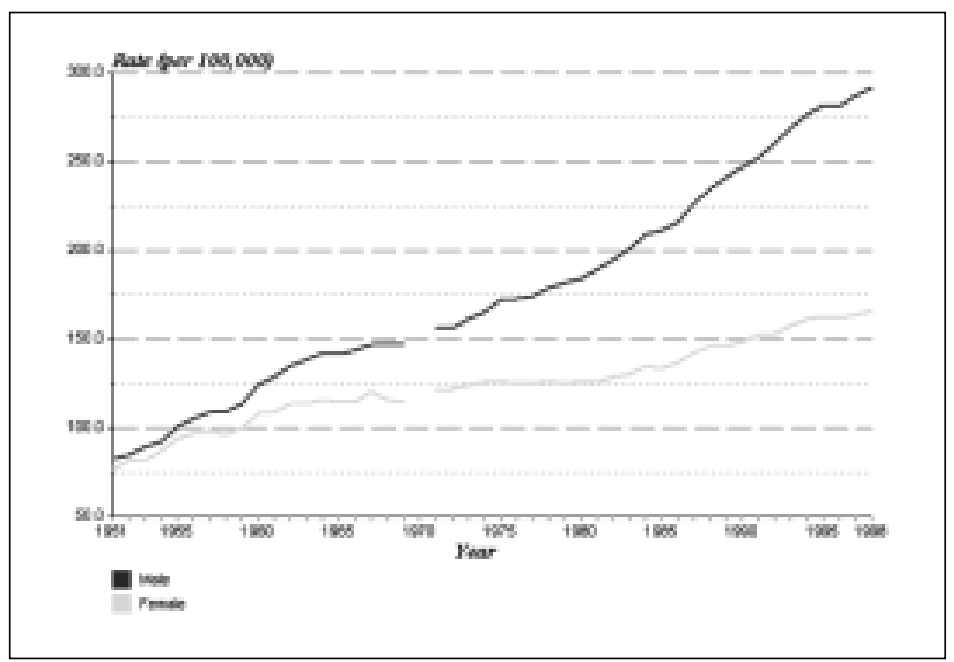

Gráfico 3: Mortalidade por todas as neoplasias, por 100.000 homens e 100.000 mulheres, Canadá, entre 1950 e 1997.

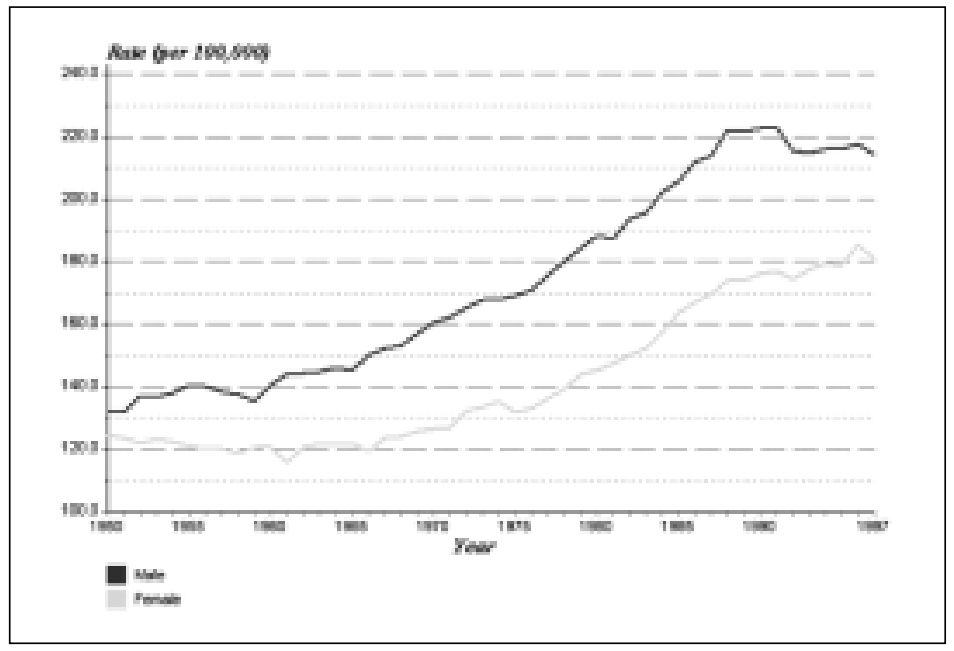

N a série brasileira, de 1979 a 1999, notase que, tanto entre homens ( $G$ ráfico 5 ) como entre mulheres (G ráfico 6 ), a mortalidade por câncer de estômago diminuiu, enquanto que se estabilizou a mortalidade por câncer do colo uterino e, entre os homens, de esôfago. Entre as mulheres, observou-se 0 crescimento da mortalidade pelos tumores de mama e pulmão, sendo que, no caso do de mama, podeter tido início uma estabilidadeem 1998, mantendo-se em ascensão a taxa de mortalidade por câncer de pulmão e observando-se um discreto aumento, no caso do câncer do cólon e reto. Já entre os homens, notou-se o aumento da mortalidade por câncer de pulmão, próstata e cólon e reto.

0 quetem ocasionado esse comportamento?

A par de que, no Brasil, o contexto sanitário é o de um país que alcançou a transição demográfica, ao mesmo tempo que um desenvolvimento desigual, o M inistério da Saúde, nos últimos anos, por meio de seus órgãos operacionais e técnicos, entre os quais se inclui o Instituto $\mathrm{N}$ acional de $\mathrm{C}$ âncer, vem envidando gigantescos esforços e progressivamente ampliando 0 acesso a assistência à saúde, tanto preventiva quanto terapêutica, melhorando os seus sistemas de informação e incorporando tecnologia.

Do ponto de vista da assistência oncológica, que é parte do controle do câncer, a regulamentação técnico-gerencial e a descentralização progressiva, dadas pelas portarias ministeriais 3.535 (estruturação dos serviços oncológicos e reorganização do nível terciário no sistema de alta complexidade em O ncologia) e 3.536 (novas regras para autorização, cobrança e pagamento de procedimentos quimioterápicos e radioterápicos), ambas de 02 de setembro de 1998, iniciaram as diretrizes para o mapeamento da oferta e demanda pela prestação desses serviços, com o conseqüente aumento do aporte financeiro.

Apenas para se ter uma idéia da conseqüência dessas iniciativas, em 2001, com procedimentos de quimioterapia, radioterapia e cirurgia oncológica, foram gastos no SUS mais de R \$ 662,3 milhões, contra cerca de R \$393,8 milhões, em 1997. Em termos da produção de serviços, esse aumento correspondeu a uma variação, para mais, de $66,5 \%$ nos procedimentos de quimioterapia, de $9,1 \%$ nos de radioterapia 
e de $89,1 \%$ nos de cirurgia oncológica, com aumentos respectivos nos gastos de $85,3 \%$, $25,4 \%$ e $89,1 \%$. A utilização máxima da capacidade instalada de radioterapia, expressa pelo seu menor percentual de crescimento relativamente às outras modalidades terapêuticas, levou ao desenvolvimento de projetos de atualização tecnológica e de expansão planejada da oferta de serviços, como o Projeto de Reequipamento Hospitalar e o Projeto Expande. (Pelo Projeto de Reequipamento $\mathrm{H}$ ospitalar, foram injetados mais de US\$ 100 milhões na aquisição de equipamentos nacionais e importados, instalação, treinamento e despesas com importação de 285 equipamentos de endoscopia, radiologia e radioterapia para 56 hospitais públicos e filantrópicos, dos quais 15 no sistema da assistência oncológica. Já o Projeto Expande, cujo investimento é de R\$ 44 milhões, vem sendo implantado desde 2000, com o objetivo de aumentar a capacidade instalada do SU S para uma assistência oncológica integral e integrada das sete modalidades assistenciais exigidas de um CACON, de modo a incluir, em quatro anos, 14 milhões de brasileiros nessa assistência).

De que forma estes números podem ser correlacionados com a evolução das taxas de mortalidade dos diversos tipos de tumores?

Para responder a esta questão, impõe-se iniciar um processo de avaliação planejado do sistema de assistência oncológica no Brasil que, no SUS, neste final do ano de 2002, soma 280 unidades cadastradas, sendo 92 CACON sem radioterapia, 83 CACON com radioterapia, 67 Serviços I solados de Q uimioterapia e 38 Serviços I solados de Radioterapia.

0 que isso representa em termos de cobertura populacional e de efetiva prestação de serviços é estimado em um trabalho que está sendo publicado neste número da R evista Brasileira de Cancerologia e que demonstra a necessidade de se evoluir para um melhor conhecimento da realidade, dentro e fora do SU S; para o estímulo à prestação de serviços integrados por unidades já cadastradas, sob a regulação dos fluxos de encaminhamentos dos doentes; para o cadastro de novas unidades somente com a garantia do cumprimento das normas ministeriais vigentes, em termos epidemiológicos, estruturais e operacionais; e para um efetivo controle e avaliação dos procedimentos aplicados.
G ráfico 4: Mortalidade por todas as neoplasias, por 100.000 homens e 100.000 mulheres, Brasil, entre 1979 e 1999.

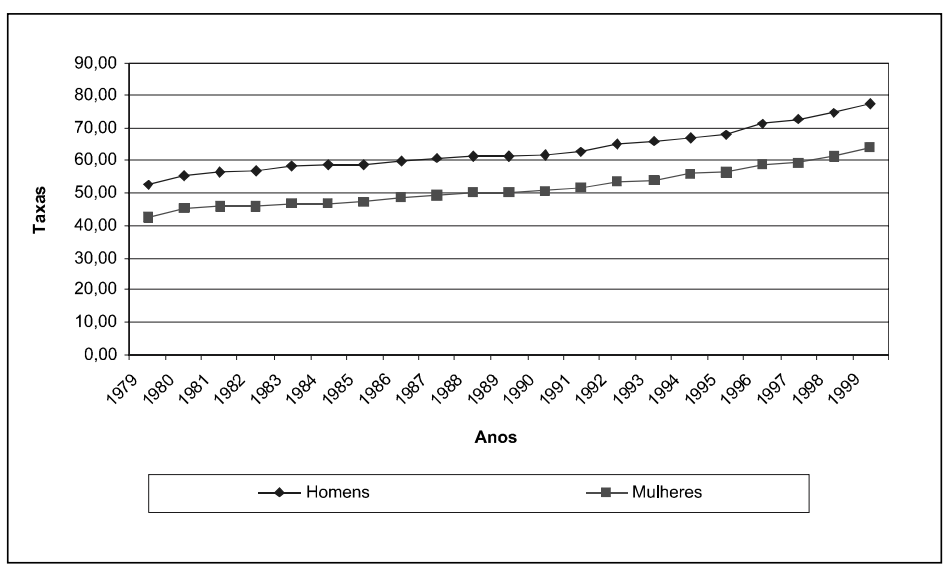

G ráfico 5: Mortalidade por câncer, Brasil, entre 1979 e 1999, por 100.000 homens, das 5 localizações primárias mais freqüentes.

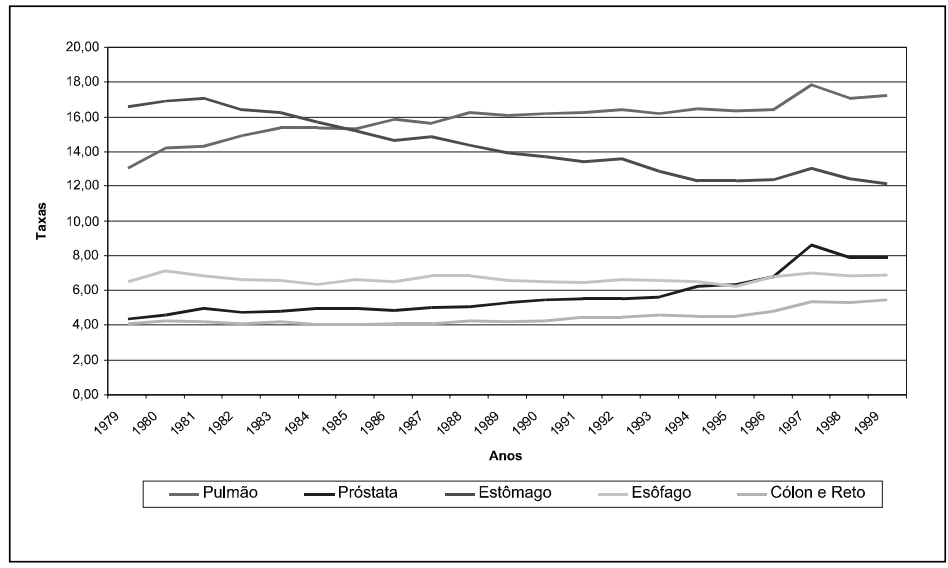

Gráfico 6: Mortalidade por câncer, Brasil, entre 1979 e 1999, por 100.000 mulheres, das 5 localizações primárias mais freqüentes.

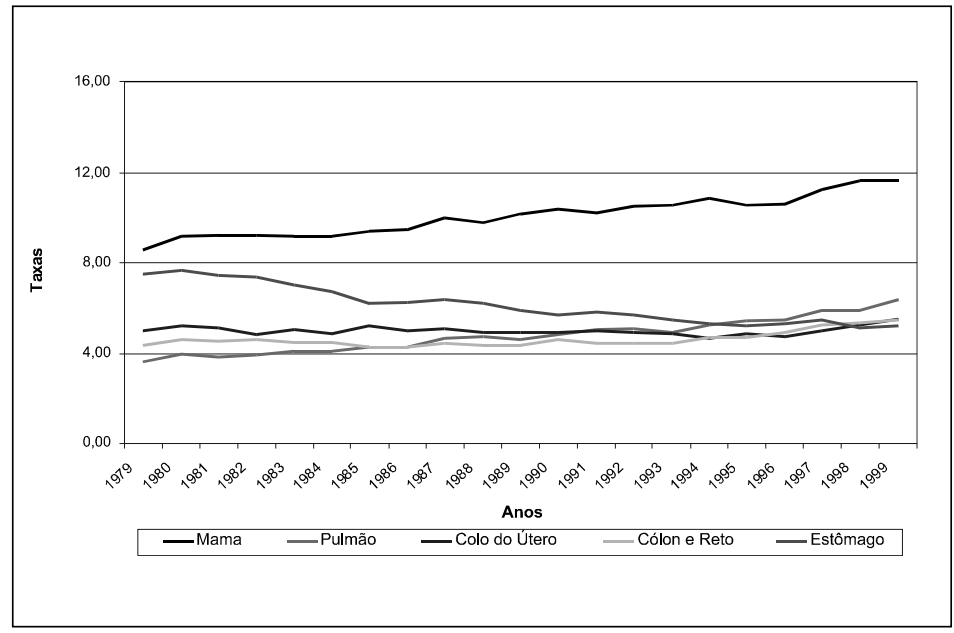


H á de se ter pulso e respaldo político para que se inicie a correção de distorções que tão gravemente persistem no sistema de saúde de brasileiro como um todo. Faz parte do dever dos gestores, em todos os níveis e áreas, cuidar para que, tanto no âmbito do SU S como no do sistema privado, regras mínimas sejam obedecidas, em termos da quantidade e da qualidade necessárias para uma boa assistência à saúde.

Jacob Kligerman Diretor Geral Instituto $\mathrm{N}$ acional de Câncer M inistério da Saúde Kligerman@inca.gov.br

\section{Bibliografia Consultada}

M inistério da Saúde. Secretaria de Assistência à Saúde (Brasil). Relatório de G estão 1998/2001. Braślia: SAS/M S; 2002.219p.

M inistério daSaúde. Instituto $N$ acional deC âncer (Brasil). Atlas demortal idade por câncer no Brasil: 1979-1999. Rio deJ aneiro: IN CA; 2002. 406 p. N egri B, D i Giovanni G, organizadores Brasil, radiografia dasaúde. São Paulo: Unicamp; 2001. 588 p.

World $\mathrm{H}$ ealth $\mathrm{O}$ rganization. $\mathrm{N}$ ational $\mathrm{C}$ ancer $\mathrm{C}$ ontrol Programmes: policies and managerial guidelines. 2nd ed. G eneva: W H 0 ; 2002. 180 p. 